\title{
Can climate models capture the structure of extratropical cyclones?
}

Article

Published Version

Catto, J. L., Shaffrey, L. C. and Hodges, K. I. (2010) Can climate models capture the structure of extratropical cyclones? Journal of Climate, 23 (7). pp. 1621-1635. ISSN 1520-0442 doi: https://doi.org/10.1175/2009JCLI3318.1 Available at https://centaur.reading.ac.uk/5769/

It is advisable to refer to the publisher's version if you intend to cite from the work. See Guidance on citing.

Published version at: http://journals.ametsoc.org/doi/abs/10.1175/2009JCLI3318.1

To link to this article DOI: http://dx.doi.org/10.1175/2009JCLI3318.1

Publisher: American Meteorological Society

All outputs in CentAUR are protected by Intellectual Property Rights law, including copyright law. Copyright and IPR is retained by the creators or other copyright holders. Terms and conditions for use of this material are defined in the End User Agreement.

\section{www.reading.ac.uk/centaur}

\section{CentAUR}

Central Archive at the University of Reading

Reading's research outputs online 


\title{
Can Climate Models Capture the Structure of Extratropical Cyclones?
}

\author{
JENNIFER L. CATTO \\ Department of Meteorology, University of Reading, Reading, United Kingdom \\ LEN C. SHAFFREY \\ National Centre for Atmospheric Science, Department of Meteorology, University of Reading, Reading, \\ United Kingdom
}

KEVIN I. HODGES

Environmental Systems Science Centre, University of Reading, Reading, United Kingdom

(Manuscript received 26 June 2009, in final form 2 November 2009)

\begin{abstract}
Composites of wind speeds, equivalent potential temperature, mean sea level pressure, vertical velocity, and relative humidity have been produced for the 100 most intense extratropical cyclones in the Northern Hemisphere winter for the 40-yr ECMWF Re-Analysis (ERA-40) and the high resolution global environment model (HiGEM). Features of conceptual models of cyclone structure-the warm conveyor belt, cold conveyor belt, and dry intrusion-have been identified in the composites from ERA-40 and compared to HiGEM. Such features can be identified in the composite fields despite the smoothing that occurs in the compositing process. The surface features and the three-dimensional structure of the cyclones in HiGEM compare very well with those from ERA-40. The warm conveyor belt is identified in the temperature and wind fields as a mass of warm air undergoing moist isentropic uplift and is very similar in ERA-40 and HiGEM. The rate of ascent is lower in HiGEM, associated with a shallower slope of the moist isentropes in the warm sector. There are also differences in the relative humidity fields in the warm conveyor belt. In ERA-40, the high values of relative humidity are strongly associated with the moist isentropic uplift, whereas in HiGEM these are not so strongly associated. The cold conveyor belt is identified as rearward flowing air that undercuts the warm conveyor belt and produces a low-level jet, and is very similar in HiGEM and ERA-40. The dry intrusion is identified in the 500-hPa vertical velocity and relative humidity. The structure of the dry intrusion compares well between HiGEM and ERA-40 but the descent is weaker in HiGEM because of weaker alongisentrope flow behind the composite cyclone. HiGEM's ability to represent the key features of extratropical cyclone structure can give confidence in future predictions from this model.
\end{abstract}

\section{Introduction}

To have confidence in predictions of future climate, it is necessary for current climate models to be able to adequately represent extratropical cyclones, from the spatial distribution of storm tracks down to the structure of the storms. Extratropical cyclones are important for providing the day-to-day variability of weather in the midlatitudes. The most intense of these extratropical

Corresponding author address: Jennifer Catto, Dept. of Meteorology, University of Reading, Earley Gate, P.O. Box 243, Reading RG6 6BB, United Kingdom.

E-mail: j.l.catto@reading.ac.uk cyclones can have huge socioeconomic impacts due to their associated strong winds and heavy rain. It is possible that with a changing climate, these impacts may be more severe or located in different regions. For example, Bengtsson et al. (2009) found that in the Max Planck Institute atmosphere model (ECHAM5; Roeckner et al. 2003), the wind speeds related to extratropical cyclones remained fairly constant in a future climate scenario but the associated rainfall increased and became more extreme. Extratropical cyclones are mainly driven by the strong temperature and moisture gradients across the polar front and often develop in the baroclinic regions over the Gulf Stream or Kuroshio Current in the Northern Hemisphere. These transient systems play an important 




FIG. 1. Schematic showing WCB, CCB, and dry intrusion (adapted from Browning 1997).

role in the large-scale atmospheric circulation as they travel from west to east across the ocean basins, transporting heat and moisture from the equator to the poles. It is therefore very important for climate models to represent the dynamical processes and airflows of extratropical cyclones in order to be able to correctly predict the large-scale atmospheric flow.

This study aims to investigate how well the structures of the most intense extratropical cyclones are represented in the high resolution global environment model (HiGEM; Shaffrey et al. 2009), which is a coupled climate model. This will be evaluated against the 40-yr European Centre for Medium-Range Weather Forecasts (ECMWF) Re-Analysis (ERA-40). Because identical cyclones cannot be compared between models and reanalysis, a compositing methodology has been used. This allows a statistical comparison to be made between the extratropical cyclones in the model and those from the reanalysis dataset. Using this compositing it is possible to identify the key features present in the cyclones. Conceptual models of cyclone structure are then used to guide the comparison between model and reanalysis storms.

Our understanding of the structure of extratropical cyclones has developed through numerous case studies of individual cyclones. The early ideas of Bjerknes and Solberg (1922) of different air masses battling at the polar front led to more detailed analysis. Harrold (1973) first described the warm conveyor belt (WCB) flow within a cyclone. Since then there have been a number of studies that attempt to generalize the theory of extratropical cyclone structure using individual case studies (e.g., Browning and Roberts 1994; Neiman and Shapiro 1993). Others have used a number of cyclones from observational campaigns (e.g., Deveson et al. 2002). These studies have produced models that show conceptually the structure of, and the flows within, cyclonic systems including the warm and cold conveyor belts and the dry intrusion. A schematic of these can be seen in Fig. 1 (after Browning 1997). The conveyor belts are defined in a frame of reference moving with its associated low pressure system. The WCB is typically a stream of warm moist air that originates at low levels in the warm sector and travels parallel to the cold front. When it reaches the surface warm front the WCB rises rapidly along the moist isentropes. As this warm air ascends, it forms the frontal cloud and the large mass of cloud often called the cloud head, which can both be identified through satellite images such as that in Fig. 2. After the rapid ascent the WCB turns anticyclonically and can be seen moving with the upper-level jet (Carlson 1980). Eckhardt et al. (2004) produced a climatology of warm conveyor belts using trajectory analysis and found that most Northern Hemisphere winter cyclones have an associated strong WCB.

The cold conveyor belt $(\mathrm{CCB})$ initially travels rearward relative to the cyclone at low levels parallel to and on the cold side of the warm front. Carlson (1980) first identified the CCB with his isentropic analysis of a single storm. This theory was taken forward by Schultz (2001) who found that the CCB mainly turns cyclonically at low levels around the low pressure producing a low-level jet. The relatively narrower and less frequently occurring anticyclonic path of the CCB spreads out in the cloud head as it ascends.

The dry intrusion consists of cold dry air that descends behind the cyclone and fans out. Some of the air turns 


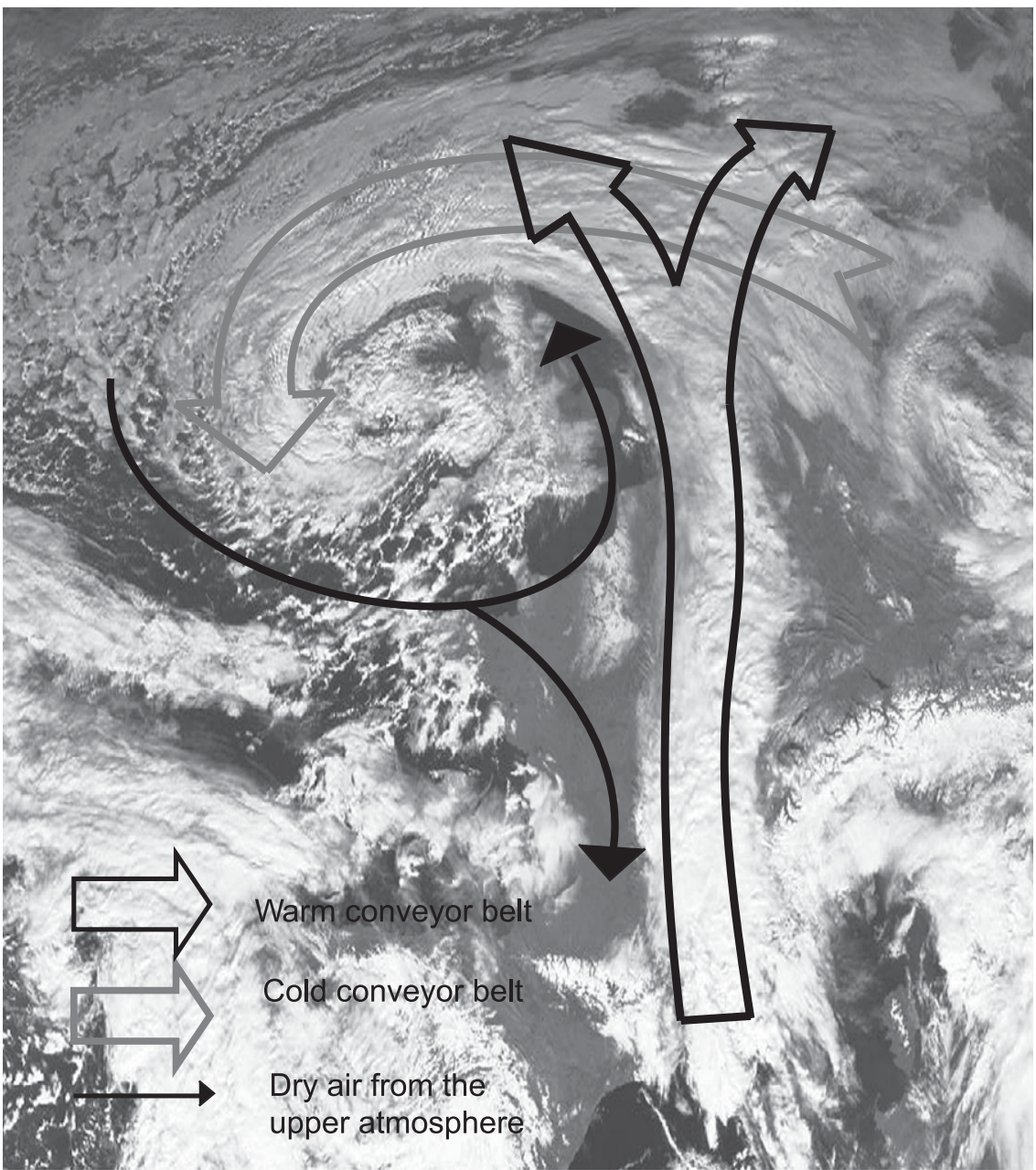

FIG. 2. Satellite image for 1200 UTC 3 Feb 2009 from Meteosat SEVIRI visible channel. Conceptual features are annotated on the image (image courtesy of NERC Satellite Receiving Station, Dundee University, Scotland; http://www.sat.dundee.ac.uk/).

anticyclonically to low levels, and some turns cyclonically and overruns the warm air. This cyclonic flow creates the common cloud-free region (the dry slot) that is identified as a cloud-free region in satellite images. An example of this is shown in Fig. 2. The dry intrusion air often originates near a tropopause fold (Browning 1997). As the descending dry air turns cyclonically, it sometimes overruns the warm air causing potential instability, which can result in convective clouds on the edge of the dry slot.

The key structural features described above are a good starting point to guide the evaluation of the structure of extratropical cyclones in climate model data. Using compositing methods it is possible to find the average properties of certain types of storms or storms located in particular regions. Recently there have been a number of studies using a variety of compositing tech- niques to investigate various questions related to extratropical cyclones. For example, Manobianco (1989) and Wang and Rogers (2001) both used ECMWF analyses to produce cyclone-centered composites of explosive cyclones from over the North Atlantic, with the aim of understanding the structure and development mechanisms of these storms. Dacre and Gray (2009) used another objectively tracked cyclone climatology produced using Met Office operational analyses to investigate development characteristics of storms in the Atlantic. Recently Field and Wood (2007) developed a compositing technique using satellite observational data and went on to evaluate the distribution of clouds and precipitation in cyclones in the National Center for Atmospheric Research (NCAR) Community Atmosphere Model (CAM3; Field et al. 2008). Bauer and Del Genio (2006) studied the distribution of moisture 
in composites of extratropical cyclones in the Goddard Institute for Space Studies (GISS) GCM with comparison to reanalyses. Bengtsson et al. (2009) took composites of the 100 most intense cyclones from ERA-40 and the ECHAM5 to compare the surface winds, mean sea level pressure (MSLP), and precipitation for presentday climate and went on to investigate changes with a warming climate. In the present study the compositing method is used to look at the structure of the cyclones in ERA-40 and HiGEM in much more detail. Using both horizontal and vertical composites of many different variables, a much more detailed understanding of the structure of the cyclones in HiGEM and ERA-40 can be gained and interpreted within the framework of conceptual models.

One of the key questions is whether the horizontal resolution of climate models used in the Intergovernmental Panel on Climate Change (IPCC) Fourth Assessment Report (AR4), which is typically between $1.5^{\circ}$ and $3.0^{\circ}$ (Randall et al. 2007), is sufficient to adequately represent the structure of extratropical cyclones, some of the features of which may be much smaller than the grid length. HiGEM (Shaffrey and et al. 2009) is a new coupled climate model based on the Hadley Centre Global Environment Model (HadGEM1; Johns et al. 2006) with a horizontal resolution of $0.83^{\circ}$ latitude $\times$ $1.25^{\circ}$ longitude (N144). We might expect that at higher resolution, extratropical cyclones may be better resolved (Jung et al. 2006).

In this study, a fully automated, cyclone-centered compositing scheme is used that takes into account the different stages of the cyclone life cycle, as well as the direction in which the cyclone is traveling. The emphasis of this paper is on extreme cyclones, so composites of the 100 most intense cyclones in the Northern Hemisphere from HiGEM and ERA-40 have been produced. Using the features of the observation-based conceptual model shown schematically in Fig. 1 (e.g., Browning and Roberts 1994; Schultz 2001) to guide a comparison between the cyclones in ERA-40 and HiGEM, the following questions will be addressed.

- Using the compositing methodology is it possible to identify in the reanalysis data, the key features of extratropical cyclone structure as identified in conceptual models?

- How well does HiGEM compare to ERA-40 in the representation of these features?

The rest of the paper is structured as follows. Section 2 details the reanalysis and the model data used along with details of the cyclone tracking and compositing methodologies. Results are given in section 3 and discussion and conclusions are in section 4 .

\section{Data and methodology}

\section{a. Model and reanalysis data}

The model used in this study is HiGEM, a new coupled climate model based on the Met Office Hadley Centre model HadGEM1 (Johns et al. 2006; Ringer et al. 2006). The resolution of the model has been increased to $0.83^{\circ}$ latitude $\times 1.25^{\circ}$ longitude $(\mathrm{N} 144)$ in the atmosphere and $1 / 3^{\circ} \times 1 / 3^{\circ}$ in the ocean. Full details of the changes made to HadGEM1 to produce HiGEM can be found in Shaffrey et al. (2009). The model used here is referred to as HiGEM1.2, and the data are taken from a control run based on present-day radiative forcings. The net top of atmosphere radiation and the upper ocean are considered to be spun up after 20 years, so for this reason the first 20 years of the integration have been rejected. The cyclones considered in this study come from 50 winters (December, January, and February) from years $21-70$ of the control integration.

The data used to assess HiGEM come from ERA-40 (for more details see Uppala et al. 2005), a global, gridded dataset, which is constrained by observations. It has been used because of the length of the dataset (45 years), the spatial resolution of approximately $1.1^{\circ} \times 1.1^{\circ}$ in the tropics (T159 linear), and the temporal resolution of $6 \mathrm{~h}$. The long period of the data allows the statistics of many storms to be included in the analysis. There are, however, some problems with using a reanalysis product for verification of model data, as the reanalysis depends itself on a model. It is also highly dependent on the number of observations available and the data assimilation techniques used, and therefore the data from regions with sparse observations in the presatellite period (such as the Southern Ocean; Hodges et al. 2003) will be less constrained than in regions with many observations. In this study the focus is on storms in the Northern Hemisphere where there are stronger observational constraints on the reanalysis. Despite the issues, reanalysis products are the best datasets constrained by observations available for studies such as this.

\section{b. Cyclone identification and feature tracking}

Objective feature tracking is becoming a frequently used way to produce information on the spatial distribution and frequency of extratropical cyclones using both reanalysis and model data. Such tracking algorithms can identify cyclones by a pressure minimum (e.g., Jung et al. 2006; Löptien et al. 2008; Hoskins and Hodges 2002), geopotential height minima (Blender and Schubert 2000), or a maximum in vorticity (e.g., Sinclair 1994; Hoskins and Hodges 2002). The tracking algorithm used here is that of Hodges $(1994,1995,1999)$ and 
Hoskins and Hodges (2002) using maxima of $850-\mathrm{hPa}$ relative vorticity to identify features in the Northern Hemisphere. The main benefits to using relative vorticity rather than MSLP for the tracking are that it can pick up smaller-scale storms and can identify storms earlier in their life cycle before a closed pressure contour has been formed. Also, vorticity does not rely on extrapolation to the extent that pressure does as it is calculated directly from the winds at the chosen level. Vorticity, however, is a noisy field, so before the tracking is performed, the vorticity field is spectrally truncated at 42 wavenumbers (T42). This means that although the datasets are of differing resolutions, the tracking can be performed on the same resolution data, therefore identifying the same spatial scales. A background field of wavenumber $n \leq 5$ is also removed, a step that is more important for tracking MSLP to remove the planetaryscale waves, but which has been performed here for consistency with previous studies (e.g., Hoskins and Hodges 2002). The feature points (i.e., vorticity maxima) are identified at 6-hourly intervals and are initialized into tracks using a nearest neighbor approach and the smoothest set of tracks are achieved by minimizing a cost function. In order not to introduce noise into the composites from very short tracks, the tracks that are kept for the compositing must have lifetimes of over 4 days.

\section{c. Cyclone compositing}

The compositing methodology used here has previously been used in Bengtsson et al. (2007) to study tropical cyclone structure and in Bengtsson et al. (2009) to compare extratropical cyclones in ECHAM5 for present day and future climate forcings. A detailed description of the methodology can be found in the appendix of Bengtsson et al. (2007), but the process will also be outlined here. Figure 3 shows the three basic steps involved in the production of the composites. The first step is to select the tracks to be used. In the present study, the storms of interest are the 50 strongest storms (according to the T42 relative vorticity) occurring over the North Pacific $\left(30^{\circ}\right.$ to $80^{\circ} \mathrm{N}$ and $140^{\circ} \mathrm{E}$ to $120^{\circ} \mathrm{W}$ ) and the 50 strongest over the North Atlantic $\left(30^{\circ}\right.$ to $80^{\circ} \mathrm{N}$ and $80^{\circ} \mathrm{W}$ to $\left.20^{\circ} \mathrm{E}\right)$ for both datasets. Clearly the tracks from the two datasets will be different, however the positioning of the 50 Atlantic tracks in HiGEM (Fig. 4a) is reasonably similar to that in ERA-40 (Fig. 4c). In the Pacific, the chosen 50 storm tracks are orientated more zonally in HiGEM (Fig. 4b) than in ERA-40 (Fig. 4d), which may be the result of the stronger zonal jet over the western Pacific Ocean in the model (Shaffrey et al. 2009).

The second step (Fig. 3) of the compositing is to find the point along each track at which the required time in


3.



FIG. 3. Schematic of the three steps to the compositing. Step 1: Identify and select the tracks to be used. Here the 50 strongest storms from the Atlantic and 50 strongest from the Pacific were used. Step 2: Find the position of maximum intensity along the track and move the $20^{\circ}$ spherical polar cap grid to be centered on this position. Step 3: Rotate preferred direction of $20^{\circ}$ spherical cap to direction of storm propagation and extract the region for averaging.

the life cycle is reached, such as the time of maximum intensity or maximum growth. In this study we will concentrate on the time of maximum intensity according to the $850-\mathrm{hPa}$ vorticity. A radial coordinate system centered on the pole is created for some radius of spherical cap, for example, $20^{\circ}$, and this is rotated to lie over the 

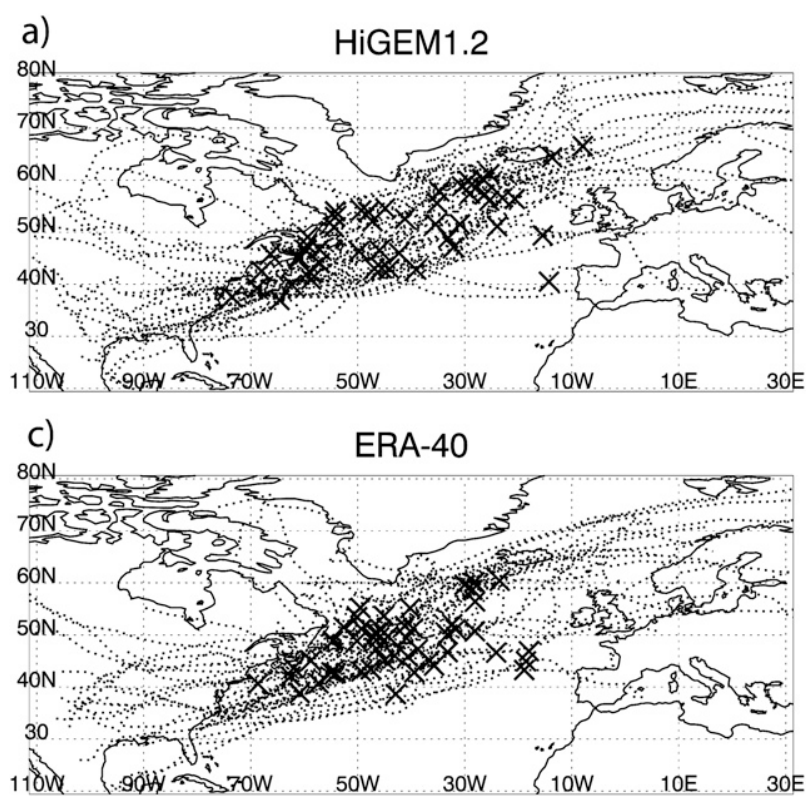

b)

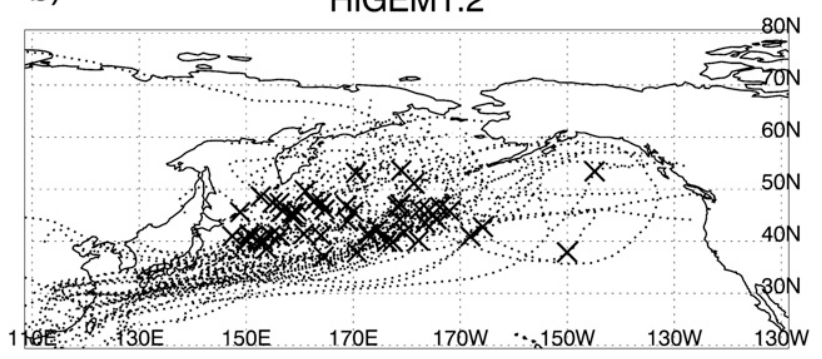

d)

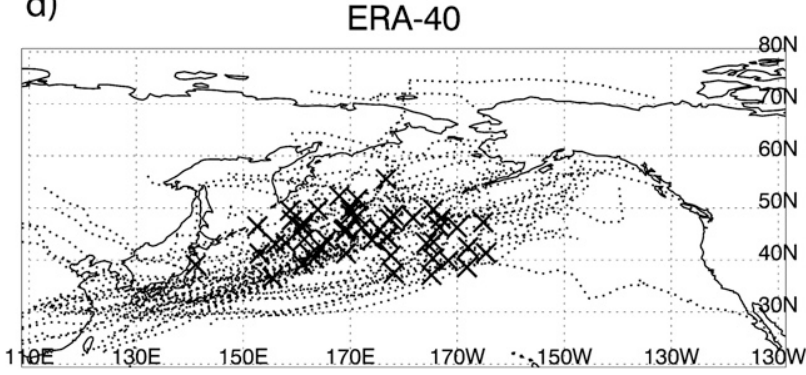

FIG. 4. The tracks used in the compositing from (a),(b) HiGEM and (c),(d) ERA-40 in the (a),(c) Atlantic and (b),(d) Pacific. Crosses indicate the position of the maximum 850 -hPa relative vorticity along the tracks.

feature point. Finally the third step (Fig. 3) is to rotate the preferred direction of this spherical cap to the direction of propagation of the storm at this point. The region is then extracted on the radial grid from the full resolution fields for averaging with the other selected storms. Using the radial coordinate system reduces the biases that can occur when using projections for the compositing, which was an issue noted in previous studies (e.g., Wang and Rogers 2001). Using the rotated composites allows a more insightful comparison between model data and reanalysis as the impact of differences in storm direction are reduced in the composite structure, and it also allows the system-relative winds to be computed more easily.

The compositing has been performed on eight pressure levels from $925 \mathrm{hPa}$ up to $200 \mathrm{hPa}$ for the horizontal and vertical winds. Since the 6-hourly temperature has only been archived for HiGEM on four levels, the compositing of temperature and relative humidity has been performed on these levels $(850,700,500,250 \mathrm{hPa})$. At each level, the $20^{\circ}$ spherical cap is extracted using the feature point at $850 \mathrm{hPa}$ as the reference. This means that the tilt of the cyclone is not taken into account. It is possible to identify the associated vorticity maxima at each level and to extract the region centered on that. The sensitivity to including this tilt was investigated but it was found that the conclusions were not altered. The tilts found were typically only a few degrees. At the mature phase at which the compositing is performed, the storms are quasi-barotropic in nature, so the tilt is less impor- tant. For these reasons this additional computational complexity was not included in this study.

\section{Evaluating the structure of extratropical cyclones}

The features of extratropical cyclones that have been described by conceptual models will now be used to guide the analysis of the composites of the 100 most intense cyclones from ERA-40 and HiGEM. This will allow the focus of the comparison to be on the most important features of the composite cyclones. First, the surface features of the composite storm will be described. Then the warm conveyor belt (e.g., Browning and Roberts 1994), cold conveyor belt (e.g., Schultz 2001), and dry intrusion (e.g., Browning 1997) will be identified in the fields of horizontal and vertical winds, temperature, and relative humidity. The sharp fronts that are seen in synoptic charts will be smoothed out by the compositing process. Even though the compositing methodology attempts to minimize this smoothing through the rotation, a key question is whether enough structure will remain in the composites in order to identify these features.

\section{a. Surface features}

In this section the key surface features of the composite storms will be described and a comparison made between ERA-40 and HiGEM. Figures 5a,b show the MSLP for the composite storms from ERA-40 and 
a)

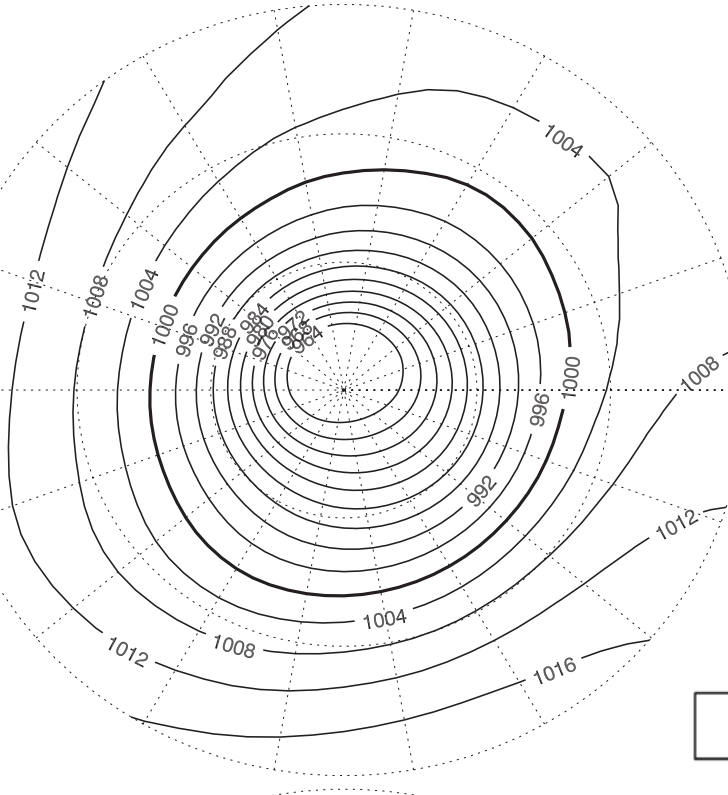

b)

)

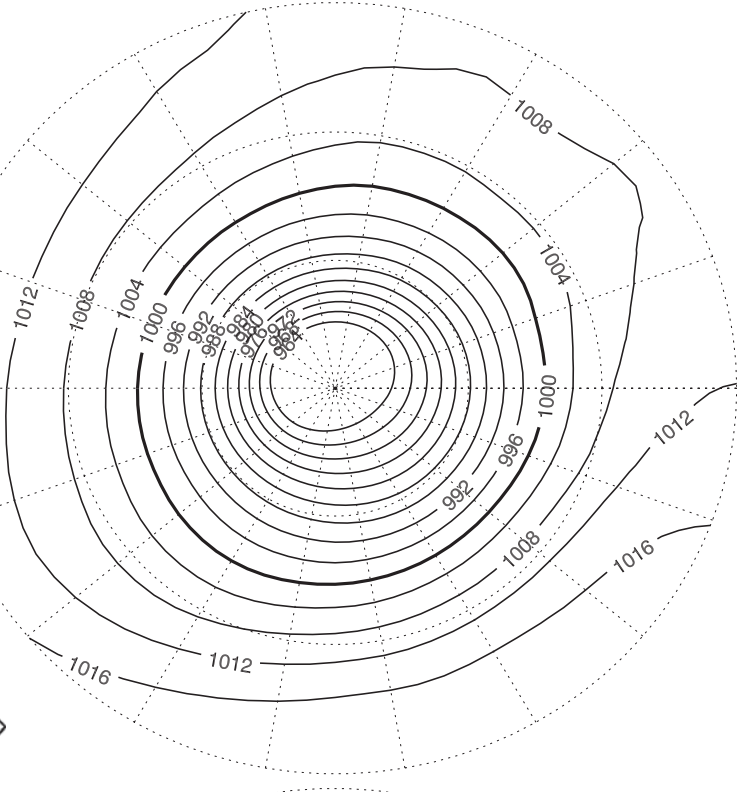

c)

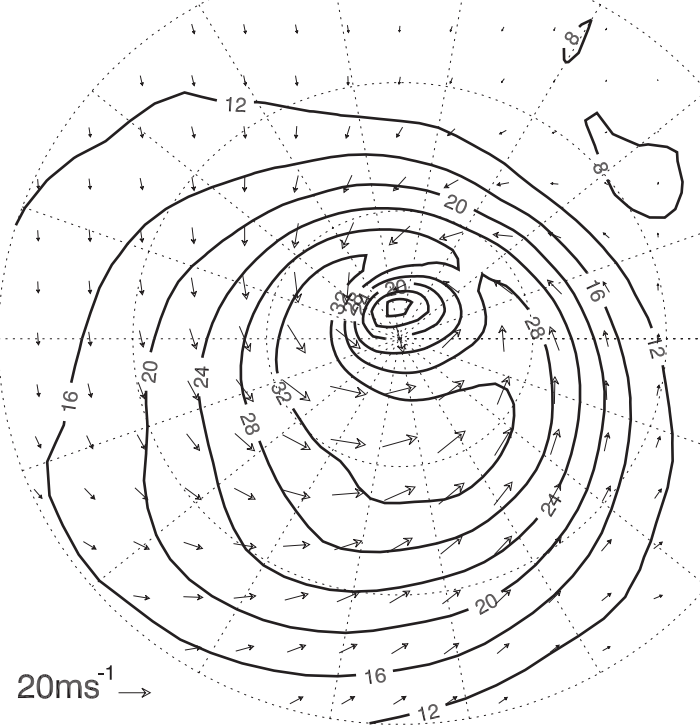

d)

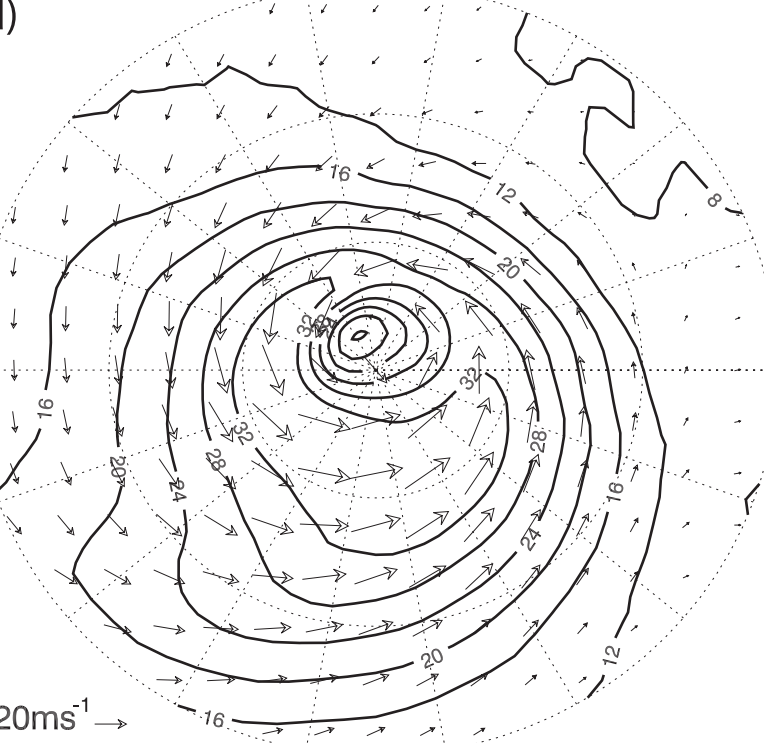

FIG. 5. Composites of MSLP (hPa) for (a) ERA-40 and (b) HiGEM. Contours are at 4-hPa intervals. The distance from the center of the composite cyclone to the edge is $15^{\circ}$. Composites of the earth-relative 925 -hPa winds with corresponding wind vectors for (c) ERA-40 and (d) HiGEM. Contours of wind speed are $4 \mathrm{~m} \mathrm{~s}^{-1}$. The large arrow indicates direction of storm propagation.

HiGEM respectively. The direction of propagation is from left to right and the radius of each plot is $15^{\circ}$. The along-propagation direction will be referred to as the $x$ direction with $u$-component winds (positive in the direction of propagation), while the cross-propagation direction will be referred to as the $y$ direction with $v$-component winds (positive from bottom to top of the plots). The minimum pressure is located approximately in the center of the composite with a value of $955.9 \pm$ $10.8 \mathrm{hPa}$ for ERA-40, and is very similar for HiGEM with a value of $954.5 \pm 10.6 \mathrm{hPa}$. (The range given here is one standard deviation.) The structure of the MSLP exhibits an elongated nature in the upper right-hand quadrant in both ERA-40 and HiGEM. This structure is consistent with the results of Manobianco (1989) and Wang and Rogers (2001), the latter of whom suggested this could be due to the existence of parent cyclones ahead and poleward of the individual cyclones in the composite. The near-surface $(925 \mathrm{hPa})$ earth-relative winds in Figs. 5c,d show the position of the maximum 


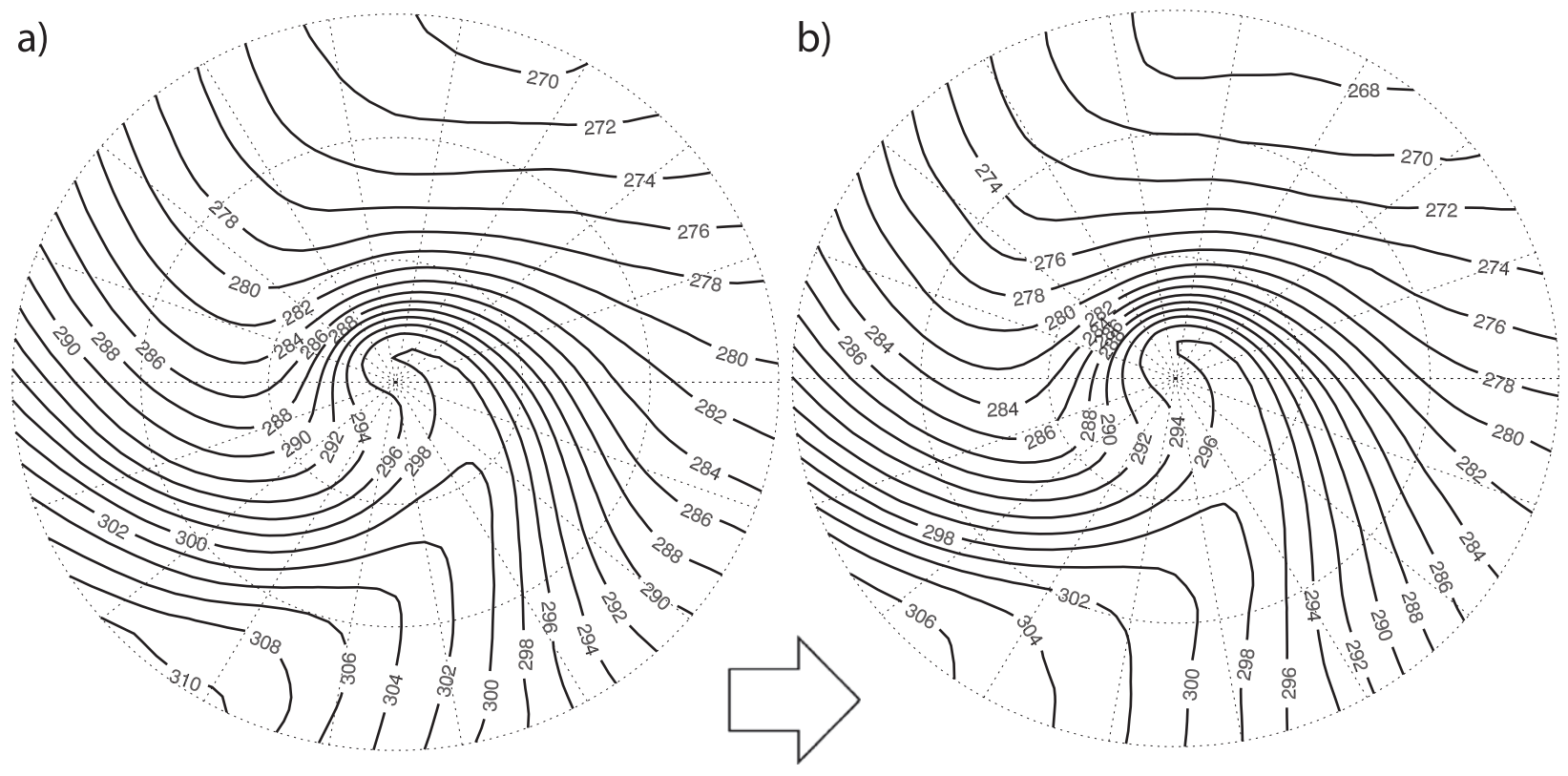

FIG. 6. Composites of equivalent potential temperature at $850 \mathrm{hPa}\left(\theta_{e} ; \mathrm{K}\right)$ for (a) ERA-40 and (b) HiGEM. Contours are at $2^{\circ}$ intervals. The large arrow indicates direction of storm propagation.

winds that would be experienced behind and to the right of the storm center. The spatial pattern of the winds are very similar between ERA-40 and HiGEM but the values in HiGEM are slightly higher, particularly in the bottom half of the plot. As can be seen in Figs. 5c,d, the distribution of winds around the cyclone is axially asymmetric. Some of the strongest winds occur in the bottom righthand quadrant of the composite cyclone where the WCB is found. To quantify the differences in the wind speeds between HiGEM and ERA-40, the maximum speed that occurs in the bottom right-hand quadrant of each cyclone was found, as well as the radial distance from the center at which it occurs. The average maximum wind speed for ERA-40 is $39.1 \pm 3.5 \mathrm{~m} \mathrm{~s}^{-1}$ at $5.1 \pm 2.7^{\circ}$ and for HiGEM is $41.5 \pm 3.7 \mathrm{~m} \mathrm{~s}^{-1}$ at $4.9 \pm 2.2^{\circ}$ indicating that the strength and position of the maximum wind speeds from HiGEM compare well against ERA-40 within the spread.

To identify the approximate position of the surface fronts the equivalent potential temperature $\left(\theta_{e}\right.$; Figs. $6 \mathrm{a}, \mathrm{b})$ at $850 \mathrm{hPa}$ is used. Ideally $\theta_{e}$ at a level closer to the surface would be used but $850 \mathrm{hPa}$ is sufficiently close to the surface to identify the key features and is the lowest level in the archived data from HiGEM. Figure 6a shows $\theta_{e}$ at $850 \mathrm{hPa}$ for ERA-40 and it can be seen that there is a strong gradient in the $y$ direction with $\theta_{e}$ decreasing in the positive $y$ direction. This represents the strong temperature and moisture gradients that exist between the tropics and the high latitudes. In the bottom right quadrant of the composite there is a region of warmer air. This is consistent with the warm sector, which is seen lying between the warm and cold fronts in a typical cyclone. The typical surface storm structure shown schematically in Fig. 1 can be identified in the composite storms from ERA-40 and HiGEM. The warm front lies ahead of the low pressure center along the line of strongest $\theta_{e}$ gradient and the trailing cold front can be seen in the lower section of Figs. 6a,b to the left of the warm air. These temperature structures resemble the Shapiro-Keyser frontal cyclone model (Shapiro and Keyser 1990) more closely than the traditional Norwegian model, although here there is no warm seclusion. It can be seen that HiGEM compares remarkably well with ERA-40 when identifying the surface features.

\section{b. Warm and cold conveyor belts}

\section{1) ERA-40}

The WCB consists of warm moist air that travels poleward from the subtropics parallel to the cold front. This air rises at the warm front as it ascends along moist isentropic surfaces. Some of the WCB air then turns anticyclonically as it gets entrained in the zonal jet. Composites of horizontal and vertical winds and temperature have been used to try to identify features that may be consistent with the concept of a WCB. Figure 7 shows the system-relative wind speeds and their corresponding vectors at 925 and $700 \mathrm{hPa}$ while Fig. 8 shows the system-relative winds at $400 \mathrm{hPa}$. The system-relative winds have been obtained by subtracting the system 


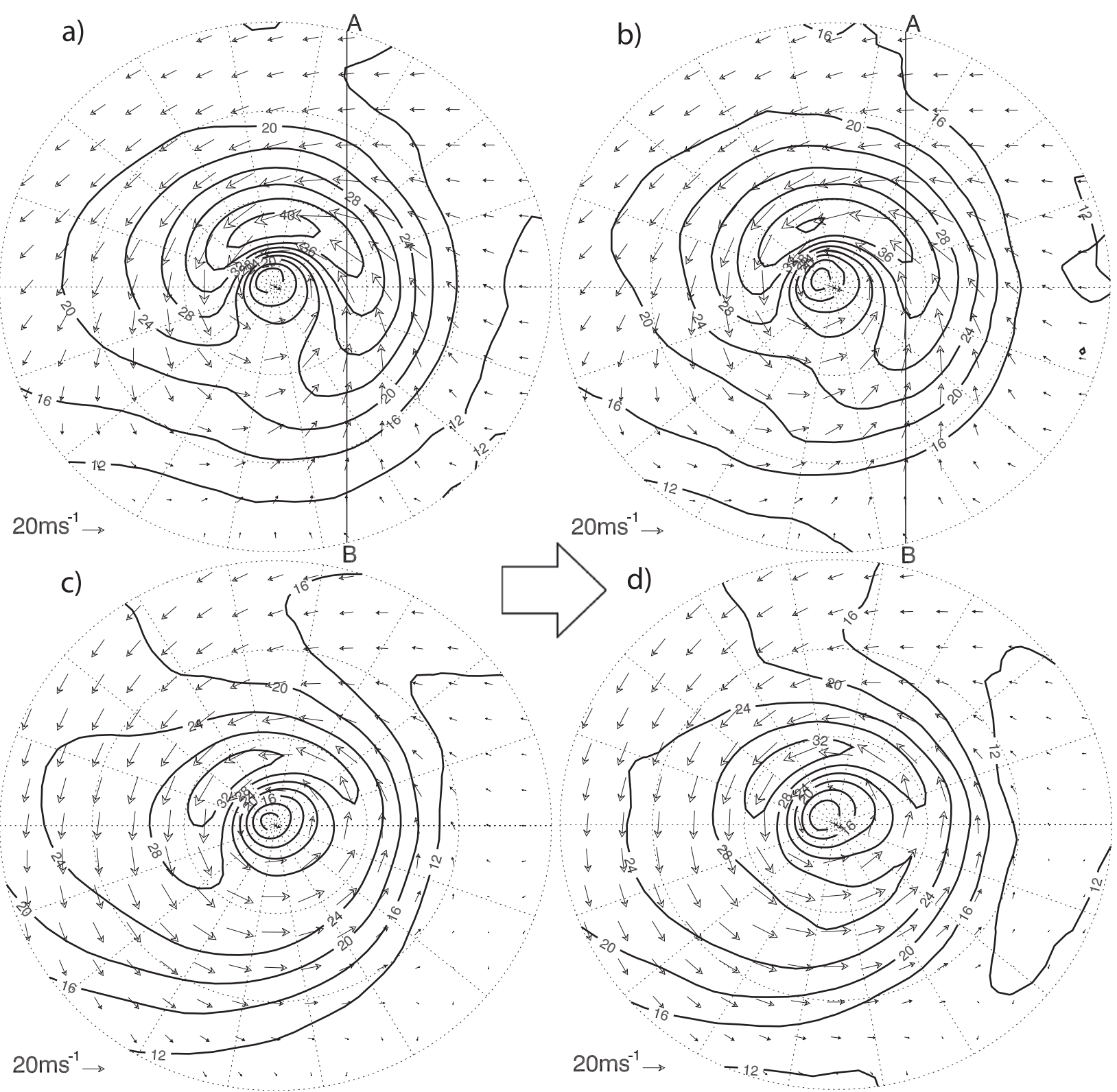

FIG. 7. Composites of system-relative winds for (a),(c) ERA-40 and (b),(d) HiGEM at (a),(b) 925 and (c),(d) 700 hPa and their associated wind vectors. Contours are $4 \mathrm{~m} \mathrm{~s}^{-1}$. The distance from the center of the composite cyclone to the edge is $15^{\circ}$. (a),(b) The line from A to B indicates the vertical slice taken to produce Fig. 9. The large arrow indicates direction of storm propagation.

velocity (calculated from the tracks) from the earthrelative winds. These have been used here as they allow the air flows within the cyclone to be identified and, as such, most conceptual model studies have used them. The system-relative winds have a different structure to the earth-relative winds shown in Figs. 5c,d. In the lower right quadrant of Fig. 7a the low-level winds have a positive $v$ component consistent with the low-level warm air present in the WCB. At the upper level of $400 \mathrm{hPa}$ (Fig. 8a) where the westerly upper-level jet dominates, there is an anticyclonic flow in the upper right quadrant of the composite cyclone. This is consistent with the idea that after the warm air in the WCB has ascended along the isentropes, it becomes entrained in the westerly jet and turns anticyclonically away from the cyclone center.

The CCB is a low-level flow of air on the cold side of the warm front that travels rearward relative to the direction of storm propagation, parallel to the warm front. Most of this air flows cyclonically around the cyclone center producing a low-level jet. Ahead of the storm 


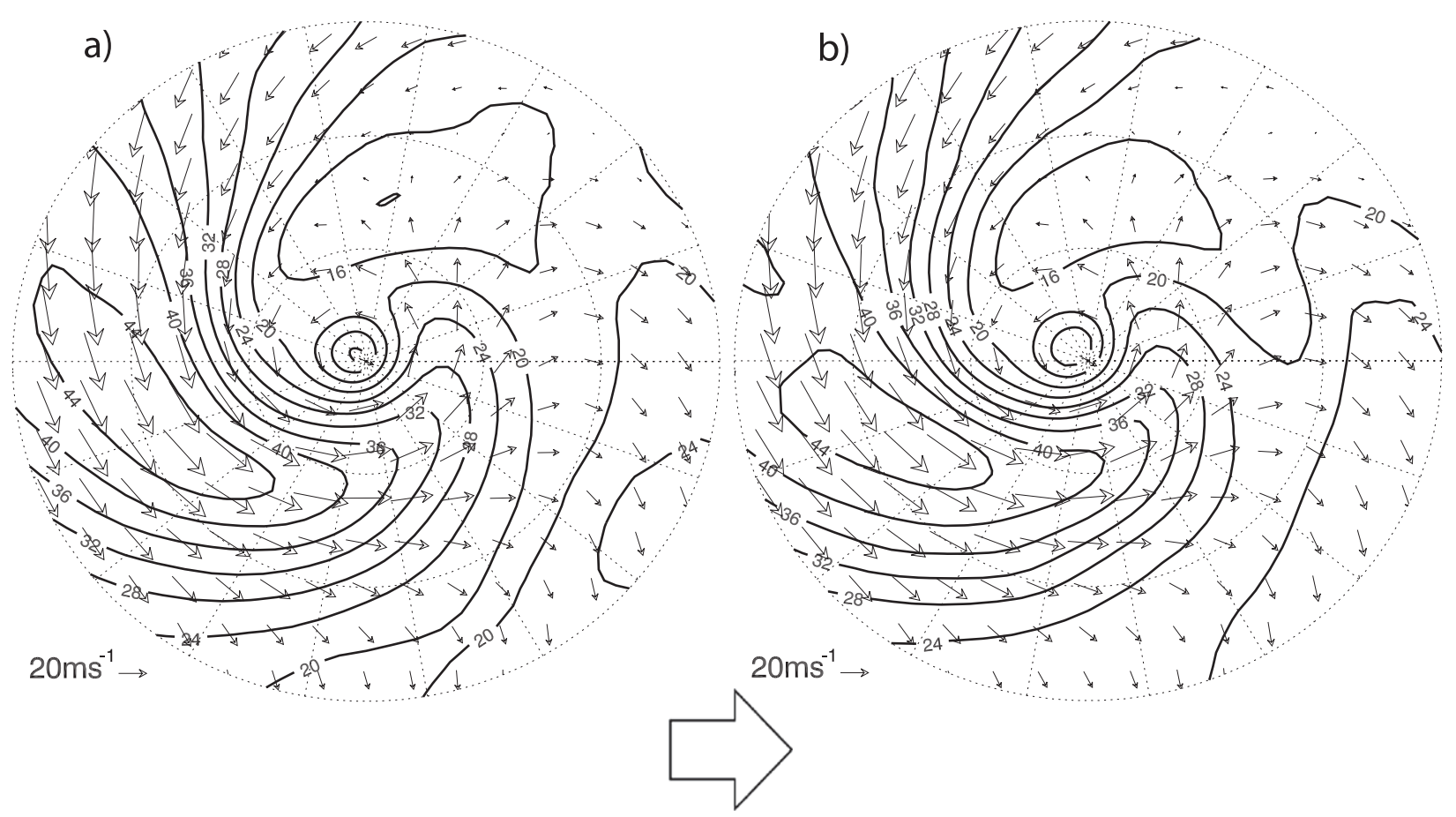

FIG. 8. Composites of system-relative winds for (a) ERA-40 and (b) HiGEM at $400 \mathrm{hPa}$ and their associated wind vectors. Contours are $4 \mathrm{~m} \mathrm{~s}^{-1}$. The distance from the center of the composite cyclone to the edge is $15^{\circ}$. The large arrow indicates direction of storm propagation.

center in the upper right-hand quadrant of Fig. 7a, at the approximate position of the warm front, the near-surface winds are flowing quite strongly rearward relative to the direction of storm propagation. The maximum wind speed at $925 \mathrm{hPa}$ is seen spiraling around the low pressure center, consistent with the $\mathrm{CCB}$ air shown in the conceptual model (Fig. 1). At $700 \mathrm{hPa}$ (Fig. 7c), the position of the maximum wind speed has shifted more toward the rear of the storm center. At this higher level, the maximum wind speed is weaker than nearer the surface.

The vertical structure of the WCB and CCB are often analyzed by taking vertical sections through the cyclones (e.g., Schultz 2001). Here a vertical section has been taken along a line perpendicular to the direction of storm propagation at $2^{\circ}$ ahead of the storm center shown in Figs. 7a,b as a line from A to B. This is the line along which the maximum $v$-component winds are seen in the warmer air. The vertical slice (Fig. 9a) shows the contours of $\theta_{e}$ for ERA-40 along with the largest wind speeds in the direction parallel to and perpendicular to the direction of storm propagation (denoted by $\mathbf{U}$ and $\mathbf{V}$ in Figs. 9a,c, respectively). The strongest $v$ component of the winds in the relatively warmer air is consistent with the strong WCB flow seen in the conceptual model. This region of strong winds tilts with height consistent with the conceptual model of the WCB air, which ascends along the warm isentropic surfaces. The ascent is shown in Fig. 9b, which is along the same vertical section but showing the vertical velocities and the regions of relative humidity greater than $90 \%$. At lower levels, the maximum ascent occurs in the warm air in the region of strong $v$-component winds and at the position of the steepest isentropes. The ascending air of the WCB produces the clouds of the frontal rainband as well as contributing to the cloud-head structure. These cloudy regions can be seen in Fig. $9 \mathrm{~b}$ as the hatched area with $\mathrm{RH}$ above $90 \%$. This area is strongly associated with the region of ascent, where the clouds form because of the isentropic uplift. The upper-level clouds have a smaller horizontal extent than those at the lower levels. In the relatively cooler air seen on the left of the composite in Figs. 9a,b, the strongest winds are flowing rearward relative to the direction of the storm underneath the warm rising air. This is again consistent with the $\mathrm{CCB}$, which flows at low levels rearward relative to the storm producing a low-level jet that undercuts the WCB.

\section{2) HIGEM}

Certain features consistent with the conceptual model WCB and CCB have been identified in the composites from ERA-40. In this section a comparison is made between HiGEM and ERA-40. The wind vectors show that in the warm sector of the composite storm the nearsurface winds are in a positive $y$ direction as in ERA-40 

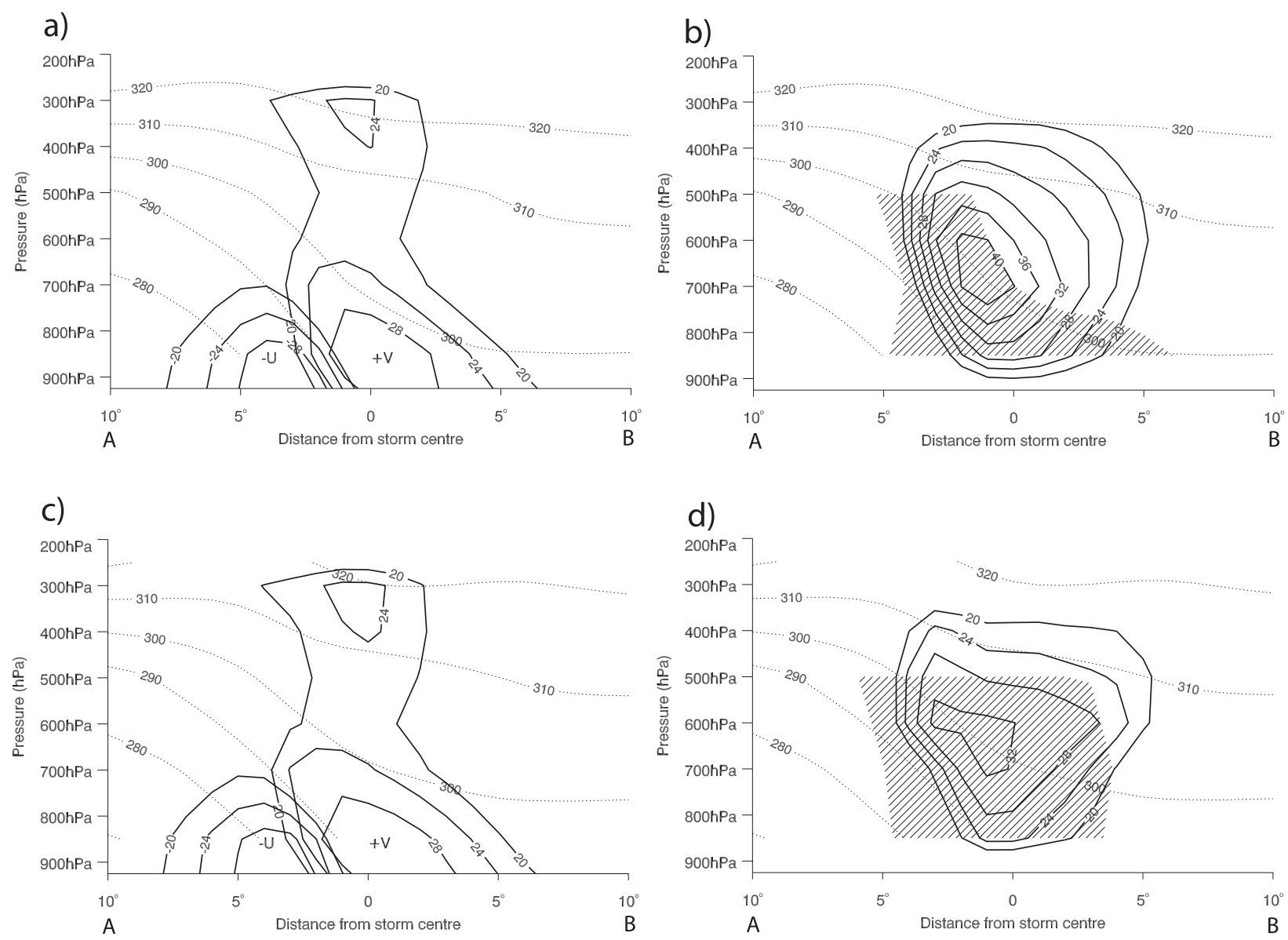

FIG. 9. Composite vertical slices through a line perpendicular to the direction of storm propagation $4^{\circ}$ ahead of the composite storm center (from A to B in Figs. 7a,b) for (a),(b) ERA-40 and (c),(d) HiGEM. The total distance in the $x$ axis is $20^{\circ}$. (a), (c) Contours of $\theta_{e}$ (K; thin dotted lines), the regions of maximum $v$ component of the wind (i.e., perpendicular to the direction of storm propagation; contour interval $4 \mathrm{~m} \mathrm{~s}^{-1}$ ) and the maximum $u$ component of the wind (parallel to the direction of storm propagation but rearward relative to the storm center; contour interval $4 \mathrm{~m} \mathrm{~s}^{-1}$ ); (b),(d) contours of vertical velocity (contour intervals $4 \mathrm{hPa} \mathrm{h}^{-1}$ ) with positive values indicating ascent and the areas with $\mathrm{RH}$ above $90 \%$ (shown by hatched area).

indicating that HiGEM appears to capture a structure consistent with the notion of a WCB. Figure 7d shows that at $700 \mathrm{hPa}$, the maximum wind speed has shifted in the same sense as ERA-40. There are some differences at this height in the structure of the wind speed contours but the position and magnitude of the maximum compare very well. At the 400-hPa level the westerly jet in HiGEM (Fig. 8b) is also the dominant feature in the composite wind field and the structure of the winds is remarkably similar to ERA-40. The anticyclonic wind vectors in the upper right quadrant of the storm imply that the WCB air is being entrained in the jet. This structure is very similar to that seen in ERA-40 (Fig. 8a). The winds directed rearward relative to the storm, which are indicative of the $\mathrm{CCB}$, are also identifiable in the HiGEM composite. The position of the $925-\mathrm{hPa}$ wind speed maximum (Fig. 7b) is very close to that of ERA-40.
Overall in the horizontal composites the features identified in ERA-40 and HiGEM compare very well.

Figures $9 \mathrm{c}, \mathrm{d}$ show the vertical section along the same line as ERA-40 (shown in Fig. 7b by the line from A to $B)$. The structure of the winds in the warmer air suggests that the flows of the WCB are very similar between HiGEM and ERA-40, as are the winds flowing rearward relative to the storm direction. The $v$-component winds tilt with height in a similar way to ERA-40. The isentropes in HiGEM show higher stratification in the warm air, to the right of the cyclone center, with the $\theta_{e}$ contours lying closer together than in ERA-40, resulting in a shallower slope to the isentropic surfaces. This shallower slope is associated with lower values of vertical velocity in HiGEM (Fig. 9d). The maximum rate of ascent in HiGEM is $33.1 \mathrm{hPa} \mathrm{h}^{-1}$ whereas in ERA-40 it is $43.7 \mathrm{hPa} \mathrm{h}^{-1}$. The position of the maximum ascent in 



FIG. 10. Composites for (a),(b) ERA-40 and (c),(d) HiGEM of 500-hPa system-relative wind vectors (see reference arrow for scale) and (a),(c) 500-hPa vertical velocity and (b),(d) RH at $500 \mathrm{hPa}$. Vertical velocity contour intervals are $4 \mathrm{hPa} \mathrm{h}{ }^{-1}$ with positive values indicating ascent. RH contour intervals are 5\%. (a),(c) The line from A to B shows the position of the vertical section shown in Fig. 11. The large arrow indicates direction of storm propagation.

HiGEM does coincide with the maximum slope of the isentropes consistent with the conceptual model of the WCB. Large differences between HiGEM and ERA-40 can be seen in the extent and structure of the region of relative humidity above $90 \%$ shown by the hatched areas in Figs. 9b,d. The cloudy area has a larger horizontal extent at upper levels compared to ERA-40. There are a number of possible reasons that the vertical temperature, cloud, and humidity structures are different in the WCB of the composite cyclones from ERA-40 and
HiGEM. The most likely explanation is that the diabatic processes that modify the air flowing through the WCB are represented differently in HiGEM and ERA-40. This will be examined in the concluding discussion.

\section{c. Dry intrusion}

\section{1) ERA-40}

The dry intrusion is a feature usually identified in satellite images (e.g., Fig. 2) as the cloud-free region just 



FIG. 11. Composite vertical slices through a line perpendicular to the direction of storm propagation $7^{\circ}$ behind the composite storm center (from A to B in Figs. 10a,c) for (a) ERA-40 and (b) HiGEM. The total distance in the $x$ axis is $20^{\circ}$. Figures show contours of $\theta_{e}$ (contour interval $10 \mathrm{~K}$; thin dotted contours), the regions of maximum $v$ component of the wind (perpendicular to the direction of storm propagation and in a cyclonic sense; contour interval $5 \mathrm{~m} \mathrm{~s}^{-1}$; thin solid contours), and the regions of the strongest descent (contour interval $4 \mathrm{hPa} \mathrm{h}^{-1}$; thick solid contours).

behind the cold front. Very dry air descends from upper levels and some of the air turns anticyclonically away from the cyclone, while some turns cyclonically up and over the cyclone (Browning 1997). Figure 10a shows the system-relative wind vectors and the vertical velocity at $500 \mathrm{hPa}$ for ERA-40, indicating the region of descent behind the composite cyclone with a maximum rate of descent of $9.7 \mathrm{hPa} \mathrm{h}^{-1}$. The wind vectors show in the region of descent that the air is turning cyclonically around the composite cyclone. This region of descent coincides with an area of very low relative humidity (RH) at the same level (Fig. 10b), suggesting that the air has come from the upper troposphere where there is very little moisture. These features are consistent with the conceptual model of the dry intrusion.

Figure 11a shows a vertical section through the dry intrusion along the line shown in Fig. 10a. The region of maximum descent occurs between 700 and $500 \mathrm{hPa}$ in a region of strong horizontal winds with a direction perpendicular to the direction of storm propagation (negative $y$ direction). The air in the dry intrusion descends along isentropic surfaces, and where the alongisentrope wind speed is greatest, the descending flow will be strongest.

\section{2) HIGEM}

In the composite cyclone from HiGEM the position of the region of descent at $500 \mathrm{hPa}$ (Fig. 10c) is very similar to that in ERA-40 but the rate of descent is smaller than in ERA-40, the maximum descent in HiGEM being $7.5 \mathrm{hPa} \mathrm{h}^{-1}$. As in ERA-40, this region of descent coincides with the very low RH (Fig. 10d), consistent with the conceptual model of the dry intrusion.
The vertical section through the dry air shown in Fig. 11b shows that there are some interesting differences in the horizontal and vertical wind fields between HiGEM and ERA-40. The $v$ component of the wind is weaker to the left of and near the center of the composite storm. This difference in horizontal wind is indicative of a weaker along-isentropic flow in HiGEM compared to ERA-40. Since the thermal structure shown by contours of $\theta_{e}$ in Figs. 11a,b is very similar in HiGEM and ERA-40, this suggests that the primary reason for the differences in the descent are due to the differences in the along-isentrope winds behind the storm.

There are some differences in the $\mathrm{RH}$ field toward the center of the composite cyclone (Fig. 10), which may have some impact on the position of the edge of the cloud head. Extremely strong near-surface winds known as sting jets, which occasionally occur in the dry slot are known to descend from within the cloud head into the dry air (Clark et al. 2005). This is an important consideration for much higher resolution models. If the positioning of this dry air is not modeled correctly this may cause difficulties in modeling the occurrence of such sting-jet events.

There is a small region ahead of the HiGEM composite cyclone center where RH is greater than $100 \%$ (Fig. 10d). This is because, in the mixed-phase cloud scheme parameterization used in HadGEM1 and HiGEM (Wilson and Ballard 1999), $\mathrm{RH}$ is diagnosed with respect to ice for temperatures below $0^{\circ} \mathrm{C}$ when there is actually a mixture of liquid and ice, resulting in supersaturation. ERA-40, however, uses a combination of $\mathrm{RH}$ calculated with respect to ice and liquid for temperatures between $-23^{\circ}$ and $0^{\circ} \mathrm{C}$ 


\section{Discussion and conclusions}

The aim of this paper is to investigate the representation of extratropical cyclones in a high resolution coupled climate model, HiGEM, and in the ERA-40 reanalysis. A compositing methodology that takes into account the direction of propagation of the storms was used to produce composites of the 100 most intense cyclones occurring over the North Atlantic and North Pacific Ocean basins found in HiGEM and in ERA-40. Certain features of conceptual models of extratropical cyclones have been used to aid the comparison of the composite cyclones from the two datasets. The key results of the study are as follows:

- The compositing methodology is capable of producing composite cyclones from the reanalysis data, which exhibit features of extratropical cyclones consistent with those from conceptual models.

- The conceptual features of the warm conveyor belt, cold conveyor belt, and dry intrusion can be identified in both the reanalysis and the model composite cyclones.

- The surface features of mean sea level pressure and equivalent potential temperature have very similar structure and magnitude between HiGEM and ERA-40.

- The structure of the near-surface wind speeds compares very well between HiGEM and ERA-40 especially in the WCB and CCB.

- Differences in the ascent ahead of the storm can be attributed to the slope of the moist isentropes in this region with steeper moist isentropes and stronger ascent in ERA-40 compared to HiGEM.

- The rate of descent behind the cyclone is lower in HiGEM compared to ERA-40, which is mainly due to the weaker winds along the isentropes in this region in the model.

The fact that the features identified in the two datasets compare so well is a good indication that HiGEM can capture the structures seen in extratropical cyclones in the ERA-40 reanalysis. This demonstrates that climate models can capture the structural features of extratropical cyclones. This gives us more confidence in future predictions of extratropical cyclones. It is unclear whether the results seen here would be robust over a range of different climate models and reanalyses. Some of the smaller-scale features, such as the narrow band of cold air traveling rearward behind the warm front are at a scale of a few grid boxes of the model grid, so it raises the question of whether a lower-resolution model could also capture the same features. It is also possible that a much higher-resolution model or reanalysis dataset could capture these features even better than seen here. These questions will be addressed through future work using different resolution models and the new reanalysis product from ECMWF (ECMWF-Interim), which, with a resolution of $80 \mathrm{~km}$ might be more appropriate for this type of study.

Another issue is that parameterizations of diabatic processes, which have a strong influence on the development of extratropical cyclones, differ between climate models. It was seen in section $3 b$ that differences occurred along the WCB in the vertical profiles of temperature and relative humidity fields between ERA-40 and HiGEM (Fig. 9). A possible suggestion for this discrepancy is that in ERA-40 the cloud appears to occur because of the large-scale isentropic uplift of the air in the WCB (Fig. 9b). In HiGEM, however, the region of cloud appears less strongly related to the isentropic uplift, suggesting that there could be convection triggered in the warm air before it ascends (Fig. 9d). It is not possible to confirm this using the compositing methodology because of the lack of 6-hourly cloud or precipitation fields but if this indeed is the case it would have impacts on the positioning of the precipitation in frontal systems.

At the scale of individual cyclones, the reanalysis is relatively unconstrained in terms of clouds and humidity, so another method needs to be found to diagnose the diabatic processes seen in the extratropical cyclone composites. For example, Field et al. (2008) used satellite observations to produce composites of clouds, rain rates, and liquid water path to assess the extratropical cyclones within the NCAR Community Atmosphere Model (CAM3). To be able to more precisely define the conveyor belt flows, isentropic or trajectory analyses could be performed. Conceptual models, such as those produced by Browning and Roberts (1994), use isentropic and trajectory analysis to identify the airstreams. Such an analysis is beyond the scope of this particular study but may lead to deeper insights into the ability of climate models to capture the structure of extratropical cyclones. The present study could also be extended to investigate the structure of extratropical cyclones at different stages of their life cycles, giving additional information on the processes captured in the model.

The issues highlighted here are areas that need future research in order to gain a more complete picture of how well extratropical cyclones are represented in a range of models and reanalyses so that we can have confidence in future predictions. Even given these issues, this study has demonstrated that compositing is a powerful tool for investigating the structure of intense extratropical cyclones from reanalysis and model data.

Acknowledgments. The authors acknowledge financial support provided by NERC. The authors thank 
ECMWF for their provision of the ERA-40 reanalysis data and Dundee Satellite Receiving Station for use of their images. The helpful comments and suggestions of three anonymous reviewers are also gratefully acknowledged.

\section{REFERENCES}

Bauer, M., and A. D. Del Genio, 2006: Composite analysis of winter cyclones in a GCM: Influence on climatological humidity. J. Climate, 19, 1652-1672.

Bengtsson, L., K. I. Hodges, M. Esch, N. Keenlyside, L. Kornblueh, J.-J. Luo, and T. Yamagata, 2007: How may tropical cyclones change in a warmer climate? Tellus, 59A, 539-561.

$\_, \ldots$, and N. Keenlyside, 2009: Will extratropical storms intensify in a warmer climate? J. Climate, 22, 2276-2301.

Bjerknes, J., and H. Solberg, 1922: Life cycle of cyclones and the polar front theory of atmospheric circulation. Geofys. Publ., 3, $1-18$.

Blender, R., and M. Schubert, 2000: Cyclone tracking in different spatial and temporal resolutions. Mon. Wea. Rev., 128, 377-384.

Browning, K. A., 1997: The dry intrusion perspective of extratropical cyclone development. Meteor. Appl., 4, 317-324.

- , and N. M. Roberts, 1994: Structure of a frontal cyclone. Quart. J. Roy. Meteor. Soc., 120, 1535-1557.

Carlson, T. N., 1980: Airflow through midlatitude cyclones and the comma cloud pattern. Mon. Wea. Rev., 108, 1498-1509.

Clark, P. A., K. A. Browning, and C. Wang, 2005: The sting at the end of the tail: Model diagnostics of fine-scale three-dimensional structure of the cloud head. Quart. J. Roy. Meteor. Soc., 131, 2263-2292.

Dacre, H. F., and S. L. Gray, 2009: The spatial distribution and evolution characteristics of North Atlantic cyclones. Mon. Wea. Rev., 137, 99-115.

Deveson, A. C. L., K. A. Browning, and T. D. Hewson, 2002: A classification of FASTEX cyclones using a height-attributable quasi-geostrophic vertical-motion diagnostic. Quart. J. Roy. Meteor. Soc., 128, 93-117.

Eckhardt, S., A. Stohl, H. Wernli, P. James, C. Forster, and N. Spichtinger, 2004: A 15-year climatology of warm conveyor belts. J. Climate, 17, 218-237.

Field, P. R., and R. Wood, 2007: Precipitation and cloud structure in midlatitude cyclones. J. Climate, 20, 233-254.

—, A. Gettelman, R. Neale, R. Wood, P. J. Rasch, and H. Morrison, 2008: Midlatitude cyclone compositing to constrain climate model behavior using satellite observations. J. Climate, 21, 5887-5903.

Harrold, T. W., 1973: Mechanisms influencing the distribution of precipitation within baroclinic disturbances. Quart. J. Roy. Meteor. Soc., 99, 232-251.

Hodges, K. I., 1994: A general method for tracking analysis and its application to meteorological data. Mon. Wea. Rev., 122, 2573-2586.

_ 1995: Feature tracking on the unit sphere. Mon. Wea. Rev., 123, 3458-3465.

1999: Adaptive constraints for feature tracking. Mon. Wea. Rev., 127, 1362-1373.
_ B. J. Hoskins, J. Boyle, and C. Thorncroft, 2003: A comparison of recent reanalysis datasets using objective feature tracking: Storm tracks and tropical easterly waves. Mon. Wea. Rev., 131, 2012-2037.

Hoskins, B. J., and K. I. Hodges, 2002: New perspectives on the Northern Hemisphere winter storm tracks. J. Atmos. Sci., 59, 1041-1061.

Johns, T. C., and Coauthors, 2006: The new Hadley Centre Climate Model (HadGEM1): Evaluation of coupled simulations. J. Climate, 19, 1327-1353.

Jung, T., S. K. Gulev, I. Rudeva, and V. Soloviov, 2006: Sensitivity of extratropical cyclone characteristics to horizontal resolution in the ECMWF model. Quart. J. Roy. Meteor. Soc., 132, 1839-1857.

Löptien, U., O. Zolina, S. Gulev, M. Latif, and V. Soloviov, 2008: Cyclone life cycle characteristics over the Northern Hemisphere in coupled GCMs. Climate Dyn., 31, 507-532.

Manobianco, J., 1989: Explosive east coast cyclogenesis over the west-central North Atlantic Ocean: A composite study derived from ECMWF operational analyses. Mon. Wea. Rev., 117, 2365-2383.

Neiman, P. J., and M. A. Shapiro, 1993: The life cycle of an extratropical marine cyclone. Part I: Frontal-cyclone evolution and thermodynamic air-sea interaction. Mon. Wea. Rev., 121, 2153-2176.

Randall, D. A., and Coauthors, 2007: Climate models and their evaluation. Climate Change 2007: The Physical Basis, Contribution of Working Group I to the Fourth Assessment Report of the Intergovernmental Panel on Climate Change, S. Solomon et al., Eds., Cambridge University Press, 589-662.

Ringer, M. A., and Coauthors, 2006: The physical properties of the atmosphere in the new Hadley Centre global environmental model (HadGEM1). Part II: Aspects of variability and regional climate. J. Climate, 19, 1302-1326.

Roeckner, E., and Coauthors, 2003: The atmospheric general circulation model ECHAM 5. Part I: Model description. Max Planck Institute for Meteorology Rep. 349, 140 pp.

Schultz, D. M., 2001: Reexamining the cold conveyor belt. Mon. Wea. Rev., 129, 2205-2225.

Shaffrey, L. C., and Coauthors, 2009: UK-HiGEM: The new UK high resolution global environment model-Model description and basic evaluation. J. Climate, 22, 1861-1896.

Shapiro, M. A., and D. Keyser, 1990: Fronts, jet streams and the tropopause. Extratropical Cyclones, The Erik Palmén Memorial Volume, C. W. Newton and E. O. Holopainen, Eds., Amer. Meteor. Soc., 167-191.

Sinclair, M. R., 1994: An objective cyclone climatology for the Southern Hemisphere. Mon. Wea. Rev., 122, 2239-2256.

Uppala, S. M., and Coauthors, 2005: The ERA-40 re-analysis. Quart. J. Roy. Meteor. Soc., 131, 2961-3012.

Wang, C.-C., and J. C. Rogers, 2001: A composite study of explosive cyclogenesis in different sectors of the North Atlantic. Part I: Cyclone structure and evolution. Mon. Wea. Rev., 129, 1481-1499.

Wilson, D. R., and S. P. Ballard, 1999: A microphysically based precipitation scheme for the UK Meteorological Office Unified Model. Quart. J. Roy. Meteor. Soc., 125, 1607-1636. 